\title{
Effect of ionizing radiation on the female reproductive system
}

\author{
Michał Skrzypek ${ }^{1, A-F \oplus}$, Artur Wdowiak ${ }^{2, A-F \oplus}$, Lech Panasiuk ${ }^{3, A, E-F \oplus}$, Magdalena Stec ${ }^{4, A-D \oplus}$, \\ Karolina Szczygieł ${ }^{1, D-E \oplus}$, Małgorzata Zybała ${ }^{2, B}{ }^{\infty}$, Michał Filip ${ }^{2, B} \odot$ \\ ${ }^{1}$ Department of Clinical Dietetics, Faculty of Health Sciences, Medical University, Lublin, Poland \\ 2 Diagnostic Techniques Unit, Faculty of Health Sciences, Medical University, Lublin, Poland \\ ${ }^{3}$ Institute of Rural Health, Lublin, Poland \\ ${ }^{4}$ Prof. W. Orłowski Independent Public Clinical Hospital / Medical Center for Postgraduate Education, Warsaw, Poland \\ A - Research concept and design, B - Collection and/or assembly of data, C - Data analysis and interpretation, \\ $D$ - Writing the article, E-Critical revision of the article, F - Final approval of article
}

\begin{abstract}
Skrzypek M, Wdowiak A, Panasiuk L, Stec M, Szczygieł K, Zybała M, Filip M. Effect of ionizing radiation on the female reproductive system.
\end{abstract} Ann Agric Environ Med. 2019; 26(4): 606-616. doi: 10.26444/aaem/112837

\section{Abstract}

Introduction and objective. The tendency towards postponement of maternity implies a greater exposure of female germ cells to damaging environmental effects, including ionizing radiation (IR). Progress in paediatric oncology, based on the use of radiotherapy, also implies the occurrence of gonadal dysfunctions and subsequent female fertility disorders. Therefore, it seems justifiable to systematize the state of knowledge concerning the effect of IR on the female reproductive system.

Brief description of the state of knowledge. A considerable part of studies concerning the effect of IR on female germ cells have been conducted on animals. Their extrapolation to humans is hindered because in animal studies high acute exposures are applied, which do not reflect human environmental exposures characterized by chronic low dose exposure. Studies on animals provide a heterogenous image, which hinders the formulation of unequivocal conclusions and indicates that radiosensitivity depends, i.a. on IR dose, stage of development of oocytes, the applied marker of the effects of IR, or on the species. LD50 of human oocytes is estimated to be below $2 \mathrm{~Gy}$. The effect of IR depends, i.a. on the dose fractionation and the age (older women are more radiosensitive). In females, the effective sterilizing dose is: at birth $20.3 \mathrm{~Gy}$, at 10 years 18.4 Gy, at 20 years $16.5 \mathrm{~Gy}$, whereas at 30 years $14.3 \mathrm{~Gy}$, which is associated with the available pool of ovarian follicles. Conclusions. Within the range of low doses received as a result of environmental exposure to IR, there is no evidence for the occurrence of either adverse pregnancy outcomes, nor fertility disorders in females. These effects may be related to the cancer radiotherapy, or exposure to high IR doses during nuclear accidents.

\section{Key words}

infertility, ionizing radiation, female reproductive health, gonadotoxic action

\section{INTRODUCTION AND OBJECTIVE}

Explanations of the etiopathogenesis of reproductive functions disorders, both in males and females, preferentially attract attention to the phenomenon of oxidative stress, consisting in the occurrence of the state of imbalance between the effect of reactive oxygen species, and biological capability for quick detoxication of reactive indirect products, or repair of the damage caused $[1,2,3]$. Oxidative stress leads to the impairment of cell membranes and disorders in the integrity of DNA, and by these mechanisms exerts a negative effect on all stages of reproduction, starting from gametogenesis and ending with the course of pregnancy [3]. The occurrence of oxidative stress may be the consequence of the effect on the body of various chemical and physical environmental factors.

Among the best recognized chemical agents which are attributable to the generation of oxidative stress, are indicated heavy metals, air pollution, plant protection products and tobacco smoke $[4,5,6,7]$. The physical factors responsible for inducing this phenomenon are electromagnetic fields [8] and ionizing radiation (IR) [9]. Health behaviours,

Address for correspondence: Michał Skrzypek, Department of Clinical Dietetics, Faculty of Health Sciences, Medical University of Lublin

E-mail: michal.skrzypek@umlub.pl

Received: 17.07.2019; accepted: 04.10.2019; first published: 12.11.2019 including nutritional [10], play an important role in the generation of oxidative stress and combatting its effects [3]. An intensification of oxidative stress and reduced efficiency of the cell-repairing mechanisms are associated with the process of ageing of the body [7]. Considering the simultaneous effect of the above-mentioned factors on the human body, it is difficult to isolate and determine the strength of the effect of individual factors on human reproductive health.

The undertaking of analyses concerning the conditioning of female fertility is justified by the current demographic situation in Poland, which is characterized by a low fertility rate. In 2017, it was 1.45, which means that per 100 women at reproductive age (15-49) there were 145 babies born, whereas in order to secure a stable demographic development of the country this rate should be at least 210-215 [11]. The low fertility rate in Poland is the result, among others, of postponing the decision to start a family and maternity. This tendency has been observed in Poland since the 1990s, and as a consequence, a transition is observed towards the highest fertility of females in the age group 30-34. Over the last 10-15 yea, in Poland, the average age of a woman giving birth for the first time has increased by 4 years [11]. The discussed tendency is associated, among others, with an increase in the number of divorces in Poland: in 2017, 65,000 marital couples were divorced [11], while in 2018 63,000 [12], as well as making new relationships, in which 
persons from broken marriages are trying to have a baby at an older age [13].

A novelty in the tendency towards late maternity observed in Poland, i.e. bearing children by women aged over 35, consists in that this tendency is currently associated with a small number of children in a family, and not, as previously, with having several children [14]. From the demographic perspective, considering the low fertility rate, the ranks of late maternity are increasing, as is the mechanism maintaining the level of fertility rate in society [14]. At the same time, the discussed trends result in accentuation of the scope of problems concerning female infertility, because male fertility is maintained until the end of the life of a man, but female fertility, to a great extent, depends on age. This is related with the irreversible reduction in the ovarian pool of oocytes; in the course of development and subsequently ageing of a woman, this pool decreases from the number 2,000,000 at birth down to 100,000 at puberty, of which 400 ovulate, and subsequently, to approximately 8,000 at the age of 40 [15], with the peak size of the pool of ovarian follicles estimated at 6-7 million during foetal life [16]. Exposure to IR, associated with the treatment by radiotherapy or occupational exposure, is one of the factors conducive to premature exhaustion of the follicle pool, which may lead to fertility disorders and premature menopause. Therefore, it is important to establish within what scope of IR doses there may occur unfavourable effects of irradiation on fertility and state of health of females. Analysis of the effect of IR on female fertility is also important in the context of progress in paediatric oncology. Annually, 130,500 cases of cancer are diagnosed in children at prepubertal age and in adolescents [16]. In the treatment of cancer, radiotherapy may be applied as the first therapy, which can also precede or supplement surgery [16].

\section{OBJECTIVE}

In the presented study, which is the second module of a cycle regarding the effect of IR on the human reproductive system, the aim for analysis will be the state of knowledge pertaining to the effect of IR on female fertility. The study aims to describe the state of knowledge concerning the effect of IR on the functioning of the female reproductive system. The presented state of knowledge, in compilation with the findings contained in the previously published article [9], would allow the development of an integral conceptualization of the role of IR in the etiopathogenesis of fertility disorders.

\section{DESCRIPTION OF THE STATE OF KNOWLEDGE}

Specificity of female gametogenesis and studies of radiosensitivity of germ cells. Gametes are formed during gametogenesis during the meiotic programme, which consists of 2 consecutive cycles of cell division (first meiotic division - MI and second meiotic division - MII), and one phase of DNA replication. In mammals, oogenesis is a complicated physiological process which differs from spermatogenesis in several respects, including morphology and differentiation of gametes, duration and location [17]. During spermatogenesis, relatively small, mobile gametes, are produced, whereas the oocyte is a large cell containing all the materials needed for the initiation and maintenance of metabolism and development of the embryo, as well as for sperm DNA repair. Spermatogenesis takes place throughout the whole active life of an adult individual, due to which males can constantly produce spermatocytes. In turn, oogenesis starts at early development, stops at birth, and restarts during the period of puberty.

In humans, at approximately week 5 of embryo development, the primordial germ cells (PGCs) migrate to the gonadal ridges [18]. After reaching the first gonad they are subject to mitotic divisions and are transformed to the oogonia [18]. Before the end of the first trimester of pregnancy, they enter prophase I of meiotic development and become first order oocytes. The maturation of their nucleus arrests at the diplotene stage of the first meiotic division [19]. At birth, the ovaries of female infants contain approximately 2,000,000 immature primary (indigenous) ovarian follicles, each of them containing immature oocytes $[15,20]$. Primary follicles are recruited to grow, and are subject to transformations in the course of folliculogenesis into the first order oocytes, and subsequently into secondary (antral) oocytes [19]. During this process, oocytes and granulosa cells mature synchronically, establishing cellular communication and creating the functional syncytium. After the period of puberty, together with the first menstruation, ovarian follicles enter the period of development which ends with cell death or ovulation (the process in which the follicle releases the oocyte).

An important element of the process of maturation of the oocytes is the resumption of meiosis, arrested at the stage of prophase of the first meiotic division [19]. In humans, folliculogenesis lasts for approximately 375 days and is a regular process, which means that any time of the reproductive life of a woman, there are follicles in the ovary at each stage of development. Folliculogenesis ends when a mature oocyte leaves the ovulatory follicle during ovulation. A competent oocyte is then released, i.e. ready for fertilization. Directly after fertilization, the zygote passes through a series of rapid mitotic divisions (segmentation), which ends with the formation of the blastocyst ready for implantation. In mice, the implantation takes place 4 days after mating, in humans at day 9, on average (between day 8 and day 12), whereas in swine and cattle not earlier than 30 days after fertilization [17]. At birth, in each mammal born, female immature oocytes are arrested at the diktiotene stage, i.e. diplotene stage of the first meiotic prophase. In humans, some oocytes will be maintained at this stage for many years. In this context, the preservation of the oocyte in an intact state is a challenge. During such an extended length of time, oocytes are exposed to undesirable environmental effects, which may induce permanent aberrations, which are potentially subject to transmission to the offspring (so-called transgeneration effects) [21].

Estimation of the level of genetic risk in females induced by IR based on animal studies, is hindered due to the aboveoutlined specificity of the biology of the development of the female germ cells. As long as the male germ cells are produced during the whole life of a male individual, and all the developmental stages of the male germ cells may be easily obtained for examinations, the pool of the female germ cells is limited, and additionally, meiosis takes place during the period of embryogenesis, and subsequently development of the oocytes is arrested until the moment when a specified 
pool of them enters the maturation process in mature females $[18,19,21]$.

Obtaining a sufficient number of offspring of exposed females to reveal mutation of low frequency is considerably hindered and manifested by the small amount of female mutation data, and results in the prevalence of data concerning the male germ cells [21]. It should be remembered that the object of inter-gender comparisons concerning radiosensitivity may be various stages of gemetogenesis, and the indicated differences may also result from variations in DNA repair competences in the male and female germ cells [21].

Mechanisms and markers of IR gonadotoxicity. The sensitivity of the living matter to IR depends of the type of radiation, irradiation dose, time when the dose was administered, type of irradiated cell and phase of cell division [9]. IR causes the radiolysis of water in cell structures, and reactive oxygen species (ROS) produced as a result, may damage DNA. Impairment of the lysosomal membranes by IR causes the release of iron ions into the cytoplasm, which increases the number of DNA damages [22]. The direct and indirect effects of IR on living matter are distinguished, where the direct effects result from energy deposition in the macroparticle (contribution of this effect to the overall result of radiation is estimated at $30-40 \%$ ), while the indirect effects are the result of absorption of radiation by the surrounding medium and formation of intermediate products (ROS), which attack the macroparticle (the contribution of this effect to overall result of radiation is estimated at $60-70 \%$ ) [22]. Damage of DNA by IR takes place in both the abovementioned mechanisms. They exert an effect on both the sugar-phosphate backbone of DNA, and nitrogen bases, causing a number of types of damage, including oxidative base damage (which is the result of ROS attack), loss of bases, damage to the single (single-strand breaks; SSBs) and or double strands of DNA (double-strand breaks; DSBs), and DNA-DNA and DNA-protein cross links [2, 22]. The effectiveness of the repair processes and proliferative cell activity decide on the biological effects of exposure to IR [22]. Unrepaired or incorrectly repaired DSBs lead to cell-killing, mutations and chromosomal aberrations [2].

DNA damage caused by IR is repaired by means of mechanisms included in DNA damage response (DDR): nonhomologous end joining (NHEJ), homologous recombination repair (HRR), single strand annealing (SSA) - which is a variant of HRR, as well as by means of NAHR (non-allelic homologous recombination) [2, 23]. It should be emphasized that SSBs are also formed in the course of normal metabolic processes generating ROS [2].

NHEJ consists in non-homologous DNA end joining, after excision of the section of DNA at the site of damage. The aim of this process is to get homologous DNA ends. This can bring about the loss of a part of genetic information, and consequently a mutation. NHEJ is regarded as a basic mechanism of DSBs repair, and errors occurring as a result of repair in this mechanism in differentiated tissues do not generate any significant risk for the body, but only in those which are formed in the dividing cells $[2,22,23,24]$. Some pathological syndromes with the lack of NHEJ proteins are characterized by an elevated morbidity due to cancerous diseases, and the absence of activity of these proteins results in high radiosensitivity [22]. The repair of DNA damage in the mechanism of NHEJ takes place with the participation of the $\mathrm{Ku}$ protein $[2,9,23,25,26]$. In turn, the pathway of repair through HRR does not pose the risk of genetic errors; however, the second identical DNA strand (sister chromatid) is necessary for this kind of DNA repair process. In addition, although NHEJ repair can be applied at all stages of the cell cycle (this is especially important in the $G_{1}$ phase [2]), due to the precondition of the presence of the sister chromatid $\mathrm{HRR}$, it is most effective only at the late phase $S$ of the $\mathrm{G}_{2}$ cell cycle [2]. The mechanism of SSA repair is also susceptible to errors, and its role is similar to that of HRR [2]. In turn, NAHR is an error-prone form of homologous recombination. HRR is the basic process of DNA at early stages of embryonic development [22]. In oocytes at the diplotene stage of meiosis I, the basic DSBs repair mechanisms are also SSA. NHEJ plays a relatively smaller role, especially with regard to the effects of low IR doses [2]. Within the range of low IR doses the cause of cell death may be the accumulation of many sublethal damages, accompanied by the ineffectiveness of the repair processes [22]. The efficiency of DNA repair processes is conditioned by the maintenance of integrity of the genome, and their inefficiency results in DNA destabilization and the risk of carcinogenesis [22].

A number of indicators are used for evaluation of the genetic effects of exposure to IR. The indicator 'dominant lethal' characteristic (DL) $[27,28]$ concerns the genetic effects caused by any physical or chemical factor which causes the death of an embryo or foetus. Studies conducted on golden hamsters, mice and guinea pigs showed that radiosensitivity investigated based on the DL criterion, depends on both the species and the stage of development of the oocytes [27, 29, $30,31,32,33,34,35,36,37,38]$.

The subsequent marker of genotoxicity of IR is the occurrence of so-called non-targeted effects (NTE). At present, the paradigm is currently being questioned according to which the basic, biologically important effect of exposure to IR is DNA damage. It has been observed that radiation-induced biological effects cannot be explained exclusively by the exposure of cells or DNA to IR, but also concerns the cells which have not been directly exposed to IR (NTE) [39]. At present, it is considered that IR induces a complex systemic cellular response, including the following types of NTE: radiation-induced bystander effect (RIBE), radioadaptive response, and radiation-induced genomic instability (RIGI) [39]. The common feature of NTE is that direct nuclear exposure is not required for its occurrence, and it occurs within the range of low doses (below 1 Gy) [39]; thus, such doses which are equivalent to the environmental, chronic human exposure to IR. NTE is related with a systemic response of the body to IR. Its components require further studies, and are important considering the fact that knowledge of such a profile may be of great importance in the area of radiation protection, as well as for increasing the effectiveness of oncologic radiotherapy [39].

The concept of genetic instability was initially used for the description of the phenomenon, the result of which is accumulation of many changes required for the transformation of a stable gene of a normal cell into an unstable gene, characteristic of cancer, which may be induced by irradiation [40]. Trans-generational RIGI may also be a biomarker of the genotoxic effects induced by IR. This refers to genetic disorders which may be transmitted to the offspring [41]. The concept of RIGI refers to the results of irradiation which 
appear in daughter cells of the irradiated cells, frequently many cell divisions after the initial irradiation. These effects include genetic changes (i.e. chromosomal rearrangements, micronuclei, gene amplifications, gene mutations, including lethal mutations or delayed reproductive cell death) occurring in the daughter cells of the initially irradiated cell [42].

The so-called radiation induced bystander effect (RIBE), first confirmed in 1992 by Nagasawa et al. [43], also evokes the interest of researchers. This effect is typically observed in cells which are in contact with irradiated cells or receive certain signals from cells exposed to IR [44]. RIBE is treated as an element of the systemic response of an irradiated body to IR.

Proteins have been identified participating in the process of DNA recombination, the presence of which may modify radiosensitivity of the reproductive cells to IR at various stages of their development, e.g. replication protein A (RPA) - which is a component of transient meiotic nodules [45], or MLH1 - which are the marker of the crossing-over (COs) process [46]. Moreover, the embryonic cells may contain detectable levels of various proteins participating in the recognition and repair of DSBs in the HR mechanism (including ATR, ATM, RAD51, BRCA1, BRCA2, MSH2 and MSH3). The presence of these proteins may result in a lower sensitivity of cells to the effects of DSBs induced by the exposure to IR, compared to other cells [47].

Knowledge concerning the problem of the effect of IR on the female reproductive system is associated with the development of radiotherapy as a treatment method in oncology. Radiotherapy causes side-effects among which are such important problem as gonadal dysfunctions in women $[48,49]$. Based on mathematic models, it is possible to determine the dose of IR, after which there occurs premature ovarian failure related with the use of IR; however, current knowledge pertaining to the gonadotoxic effects of IR still remains incomplete. A relationship is indicated between resistance to radiotherapy and an altered DDR activity in the matrix cancer cells and the initiating cancer cells, which may delineate new directions in therapy in the future [50].

The concept of a lethal dose of $50 \%\left(\mathrm{LD}_{50}\right)$ means the dose of a chemical substance or a physical factor which causes death of half of the examined population within a specified time [22]. Initial studies aimed at identification of genotoxic effects induced by IR which used this measure have been conducted on mice $[20,51]$, rats $[20,52,53,54]$, Chinese hamsters $[55,56,57]$ and guinea pigs $[58,59]$. The results were heterogenous according to the examined species and duration of irradiation.

Changes concerning the direct parameters of fertility, e.g. reduction in the number of oocytes, ovarian failure, and loss of the reproductive potential, were used as indicators of the genotoxic effects of IR only in several studies, including on mice $[20,51,60]$, guinea pigs $[58,59]$, and rats $[61,62,63]$. The results of these studies are inconsistent; however, they allow formulation of the conclusion that fertility disorders are not related with the irradiated species, but rather with the duration of exposure and the dose.

A marker/indicator of exposure to IR is also the occurrence of developmental defects, i.e. anatomical and structural, or foetal structural abnormalities. They may be caused by genetic factors or environmental effects (or a combination of both factors), exerting an effect at the stage of foetal life. Considering the complexity of the etiopathogenesis of developmental defects, few researchers connected their occurrence with exposure to IR $[27,64,65,66,67,68]$. A synthesis of research in this area is also hindered by a great variety of changes which may be considered as 'defects', and various stages of development when the observations were carried out, e.g. before and after implantation of the embryo, etc.

Genetic material mutations caused by IR may also be measured by analyzing DNA-binding proteins. In the case of the embryonic line, the synaptonemal complex (SC) was used for this purpose as a biomarker of genotoxic effects $[34,54,63]$. SC is a protein structure characteristic of meiosis I, which promotes synapsis (binding homologous chromosomes), and recombination events during the first meiotic prophase. This structure occurs in the majority of sexually reproducing organisms, including mammals [69]. SC consists of 2 lateral elements (LEs), one central element (CE) and many transverse filaments (TF) $[69,70]$. Studies confirmed that SC is indispensable for the fusion of the homologous chromosomes (synapsis) and a normal course of crossover recombination [71]. It was proved that the repair of meiotic DSBs is disturbed in the absence of SC in mice, which indicates the importance of this structure for the normal course of meiosis in mammals [71]. In cytogenetic research, SC was used as a biomarker of the genotoxic effects of exposure to IR $[34,54,63]$, as well as to cyclophosphamide [72]. It was suggested that the detection of SC anomalies is a valuable strategy for the detection of the germ-line chromosomal damage [73].

An early study by Allen et al. [73] revealed 3 main types of SC abnormalities induced by chemical mutagens in male mice: SC fragmentation, and synapsis, and heterosynapsis disorders (i.e. non-homologoous conjugation). Later research allowed an additional identification of other types of abnormalities, in the majority of cases dependent on the stage of development, among which chromosomal reorganizations occurred most often, visible as single or double circles, multivalents and rings $[54,72]$. Changes were also observed in the process of synapsis, e.g. a partial and/ or total lack of chromosomal conjugation (reflected by the presence of univalents or bivalents with uncoupled regions), or non-homologous coupling [53]. A few studies concerned genotoxic effects of exposure to IR at the early stages of meiosis (oogonia and oocytes prophase I) and were conducted on rats $[53,54,62,63]$, mice [34], Chinese hamsters [55, 56] and guinea pigs [59]. Among the above-mentioned studies, those conducted on rats and mice $[34,53,54,62,63]$ used $\mathrm{SC}$ as an indicator of genotoxic effects.

Genotoxicity of IR for female embryonic cells in mammals. In literature, many experiments in vivo have been described in which females of mammals were exposed to IR, and the object of analyses were genetic changes in the embryonic line and in the offspring $[20,51,58,59]$. Studies of the effects of exposure to IR carried out on embryonic cells of female mammals confirmed that their sensitivity to radiation depends, among others, on the radiation dose (any relationship between the dose and effect has not been precisely investigated), meiotic stage of oocytes, the applied marker of IR effects or the examined species. Considering difficulties in the study of meiosis in humans, 4 experimental model species were used for analysis of the sensitivity to radiation (mice, rats, guinea pigs and Chinese hamsters). The results obtained provided a heterogenous image, hindering the formulation 
of unequivocal conclusions. For example, when the analyzed parameters are chromosomal aberrations, DL (lethal dose) and/or congenital deformities, the sensitivity to radiation is twice as high in Chinese hamster than in a mouse $[35,55,56]$. However, in the case of chromosomal aberrations detected in $\mathrm{MI} / \mathrm{MII}$, mature oocytes of a guinea pig are more sensitive to radiation than mature oocytes of a mouse [74].

Knowledge concerning radiosensitivity of female embryonic cells comes primarily from research on mice, and to a lesser degree on rats, guinea pigs and Chinese hamsters. Genotoxic effects induced by IR were investigated at all stages of meiosis, taking into account oogonia, first order oocytes (in leptoten, zygoten, pachyten and diploten), immature oocytes (oocytes I at the stage of primary and primordial ovarian follicles), maturating oocytes (first order oocytes at the pre-antral and antral stage), and mature oocytes (oocytes of the first and the second order at the stage of preovulatory and ovulatory ovarian follicles) $[27,29,67,68]$. In addition, studies are available concerning the stages of development after fertilization, mainly at the stage of the zygote and preimplantation (to the stage of the blastocyst), and the stage after implantation $[51,58,59]$. These studies indicate that the sensitivity of oocytes to irradiation strongly depends on their phase of development.

Some studies concerned analysis of the effect of IR on oogonia and prophase I oocytes [34, 53, 54, 62, 63]. Pujol et al., $[53,54]$ analyzed the effect of 3 different doses of radiation (1 Gy, 2 Gy, 5 Gy) applied on 3 different days of gestation in rats: on day 14 (oogonia), day 16 (leptoten phase) and day 18 (zygoten phase). The degree of SC fragmentation was used as an indicator of genotoxicity. It was confirmed that irradiation considerably decreases the number of embryonic cells and increases the frequency of occurrence of SC fragmentation, and additionally, at the highest doses may induce oocyte atresia. The study demonstrated that sensitivity to IR depends on the stage of meiosis at the moment of irradiation, as well as on the IR dose. The dose of $5 \mathrm{~Gy}$ proved to be lethal for germ cells on day 14 (oogonia) and 18 (zygoten), whereas on day 16 , the dose was of a sublethal character [53].

It was additionally shown that irradiation at various moments of development of the female germ cells induces different changes with respect to SC which, in the opinion of researchers, reflects differences in radiosensitivity at various stages of meiosis [54]. Similar results were obtained by Johannisson et al. [34], when they exposed female mouse foetuses to IR at a single dose of 2 Gy on days 14, 16 and 17 of gestation. The compilation of these two studies suggests that at early stages of meiosis, the genotoxic effects induced by IR do not depend on species. Considering also other data from literature reporting studies on immature and mature oocytes, a conclusion may be formulated that mature human oocytes are more sensitive to radiation than immature oocytes. Similar observations were described in the first studies of such a profile conducted on mice $[20,64,65,68,75,76]$. This was also confirmed in later research on other model species, e.g. rats and guinea pigs. Studies on rats $[62,63]$ demonstrated that IR significantly decreases fertility of the irradiated individual animals, pre-pubertal oocytes being less sensitive to IR than post-pubertal oocytes [62]. Also, the study by Jacquet et al. conducted on guinea pigs $[33,58]$, demonstrated that chromosomal damage induced by IR depends on the stage of development of oocytes. A study by these researchers in 2005 showed that the oocytes at 2 weeks prior to ovulation and those a few hours before ovulation, are characterized by a relatively high radiosensitivity [74]. In turn, an earlier study by these researchers [33] indicated that radiosensitivity of oocytes consists in rapid changes at relatively short time intervals: oocytes irradiated at the beginning (day 3 ) of the 17day oestrous cycle, showed a small number of chromosomal aberrations, whereas when irradiated at the middle phase of the oestrous cycle (day 10), they responded by the occurrence of severe chromosome damage. Moreover, it was proven that oocytes irradiated at the middle phase of the oestrous cycle were eliminated from the ovaries within several days after entering the MII phase [33]. Investigations by Kamiguchi et al. also showed differences in radiosensitivity according to the stage of maturation of oocytes in Chinese hamster, in which early diakinesis was the most radiosensitive phase, characterized by a 15 times more frequent occurrence of structural chromosome aberrations than during dictyotene stages of diestrum [77]. In turn, Reichert et al. [68] in their study on mice, found that oocytes at a transitional stage from late dictyotene to diakinesis are characterized by high radiosensitivity. In a study by Kirk and Lyon [30], female mice were exposed to various doses of IR and fertilized at different intervals after irradiation, subsequently seeking the lethal effects (dead foetuses), or malformations in live foetuses. It was confirmed that the incidence of abnormalities tended to rise with increase in dose. For each dose, the frequency of adverse effects of irradiation increased with the prolongation of the time interval from exposure to IR. In turn, Tateno et al. in their study on Chinese hamsters, observed that oocytes are very radioresistant at pachytene, while they become remarkably radiosensitive during the phases between diplotene and early dictyate; however, they recovered radioresistance after the onset of the resting stage [57]. Changes in sensitivity to IR observed in this species were more obvious than in mice and rats.

It was also demonstrated that preovulatory oocytes are characterized by a relatively high radiosensitivity. Low doses of $\mathrm{X}$ radiation (up to $100 \mathrm{cGy}$ ) caused dose-related effects concerning the induction of chromosomal aberrations [38]. In a study by Hansmann et al. [66], doses of X radiation within the range $0.05-0.8 \mathrm{~Gy}$ were applied on preovulatory mouse oocytes. It was found that significantly more hyperploid oocytes were ovulated following irradiation with $0.8 \mathrm{~Gy}$, whereas low doses did not increase the risk of nondisjunction. In turn, structural chromosome anomalies occurred also after exposure to low doses (0.05 Gy). While applying DL as the criterion of radiosensitivity, other researchers determined that preovulatory oocytes are sensitive to IR in mice [75, 78] and rats [79]. Therefore, sensitivity to the induction of genetic disorders under the effect of IR depends on the stage of folliculogenesis, as well as the time interval between irradiation and ovulation. Considering the available data concerning female mammals (including humans), it may be presumed that the genetic sensitivity to radiation observed in women is related with the size of ovarian follicles, i.e. small ovarian follicles are more resistant to the effect of IR than large ovarian follicles. With respect to mouse embryonic cells, the sensitivity to IR is associated with the stage of folliculogenesis, where the maximum sensitivity occurs at an early stage of diakinesis (as in the case of Chinese hamster), while the lowest - at the full antral phase. A scant number of reports concerning women $[20,48,49]$ are dissimilar from the research data generated in guinea pigs, where the peak 
of sensitivity is observed at the full antral phase. Early-antral and antral ovarian follicles are characterized by a greater granular layer (from the aspect of both amount and volume) than the primary ovarian follicles, which probably protects against the genotoxic effects of IR. It seems justifiable to pose the question: Why, in some species, the immature oocytes are more resistant than the mature ones to the genotixic effect of IR? While considering this problem, it should be remembered that an ovarian follicle functions as a functional syncytium; therefore, the cause of the above-mentioned differences might be the changes in the capability of oocytes for DNA repair during their development [16]. The capability of oocytes for the repair of DNA damage and its changeability during the process of their maturation has been documented in many studies $[36,80,81,82,83,84]$. In a study by Wang et al. [85], the proteome of mouse oocytes at various stages of development was described, with consideration of the diktiotene stage of the embryonic follicle, metaphase II stage (MII), and zygote stage (fertilized oocyte). The research shows that more proteins engaged in DNA repair are detected in the MII oocytes than in the germinal vesicle (GV) oocytes or in the zygote. Differences regarding sensitivity to radiation at various stages of maturation of oocytes may be interpreted in a way that relatively mature oocytes repair genetic damage by error-prone mechanisms. This is a possible explanation why chromosomal aberrations commonly occur at the MII phase $[31,37,38,68]$. However, on the other hand, immature oocytes would not repair genetic damage, which would result in cell death and lack of offspring. Differences between species regarding genotoxic IR effects may also be ascribed to the dissimilarities in the DDR implementation; therefore, further studies are necessary to resolve discrepancies in the results obtained. Moreover, the parameters for the measurement of genotoxicity of IR used in studies are very different (i.e. chromosomal changes, cell death and congenital deformities are employed), which considerably hinders the synthesis of data and formulation of conclusions.

It is worth mentioning that the sensitivity of oocytes to IR breaks the general rule in the light of which mitotically-active cells with an active DNA replication are characterized by greater radiosensitivity, while oocytes are characterized by high radiosensitivity, despite the fact that they were arrested in development at the diplotene stage of the first meiotic division [16].

The sensitivity of human oocytes to IR differs considerably from that of other species, e.g. mouse oocytes are approximately 350-times more sensitive to $\mathrm{IR}\left(\mathrm{LD}_{50}=0.15\right.$ $\mathrm{Gy})$ than monkey oocytes $\left(\mathrm{LD}_{50}=50 \mathrm{~Gy}\right)$ [48]. In turn, radiosensitivity of human oocytes, based on analysis of the effect of total body irradiation (TBI) on the ovarian function in women subjected to TBI in the course of treatment of cancerous disease in childhood, taking into account the parameter $\mathrm{LD}_{50}$, is estimated at a level below 2 Gy [48]. Dutreix and Wambersie [15] reported that castration in a woman, manifested by the arrest of secretion of the hormones by the ovaries, takes place several weeks after disappearance of ovarian follicles, after application of the dose of 12-15 Gy in women aged 20, while in women aged 45 - after application of the dose of 5-7 Gy. Exposure to the dose of several Gy causes temporary sterilization and menstruation disorders; however, women who experience amenorrhea after exposure to the dose of 3-4 Gy could become pregnant after the return of menstrual cycles [15]. Radiosensitivity of oocytes surpasses the radiosensitivity of all mammalian cells, with early oocytes being relatively radioresistant, whereas maturating and mature oocytes are radiosensitive to an equal degree [15].

The effects of IR go beyond the gonadotoxic effect and also include (in the case of irradiation of the abdominal cavity in childhood) altered uterine vascularization, decreased uterine volume and elasticity, myometrial fibrosis and necrosis, as well as endometrial atrophy and insufficiency [16]. These changes may cause complications during the course of pregnancy, including placental disorder, foetal malposition, preterm delivery, low birth weight, as well as a high risk of uterine rupture [16].

Irradiation of the scalp also exerts an effect on fertility which - according to the dose, method of dose fractioning, and duration of exposure/treatment scheme - may result in H-P-G axis (hypothalamic-pituitary-gonadal axis) dysfunction and anterior pituitary hormone deficiency, which is the most frequent adverse effect of radiotherapy on the head in patients at developmental age, affecting sexual maturation and fertility. The mechanism of high radiosensitivity of the $\mathrm{H}-\mathrm{P}-\mathrm{G}$ axis has not been precisely recognized and is probably related with hypothalamic and pituitary cell damage caused by IR. An intensification of H-P-G axis dysfunction grows with an increase in the biological effective dose of IR [16].

Radiosensitivity of the ovaries also depends to a great degree on the age of the woman exposed to IR: the younger the patient exposed to irradiation, the greater the damage, and in the case of oncologic radiotherapy this effect may be enhanced by the use of alkylating chemotherapy, e.g. by means of cyclophosphamide. In a female at prepubertal age, exposure to a dose lower or equal 2 Gy will result in damaging a half of the oocytes, while in approximately $30 \%$ of young women and in nearly all women aged over 40 , doses within the range 25 - 50 Gy will cause infertility [16].

Generally speaking, the male germ cells are more radiosensitive than the female germ cells [21]. Radiosensitivity of the oocytes depends on age, species, inbred or outbred strain, stage of development of the follicle surrounding the oocyte, and chromosomal configuration [20]. Oocytes in primordial follicles are highly radiosensitive in mice, rats and rabbits; moderately radiosensitive in dogs, cows and pigs; and highly resistant in the guinea pig, monkey and human, whereas smaller differences in radiosensitivity are observed with respect to oocytes in multi-layered follicles [20].

Transgenerational transmission of genomic instability. Transgenerational radiation-induced genomic instability (RIGI) is a phenomenon which consists in the occurrence of an increased indicator of mutations or an increase in the frequency of the developmental deformities in the offspring of irradiated parents not exposed to the direct effect of IR [31, $37,38,68,86]$. Knowledge concerning RIGI undermines the to-date functioning paradigm which assumes that the major component of the genetic risk related with IR in humans is mutation induction in the cells directly exposed to IR [86, 87]. Preliminary evidence for the presence of transgenerational effects was provided by Lüning et al. [88], who observed RIGI in the germline cells of the offspring of parents directly exposed to IR. The researchers analyzed the frequency of occurrence of lethal mutations leading to the death of mouse embryos under the effect of ${ }^{239} \mathrm{Pu}$ citrate solution, and found that the induction of mutation takes place not only in the 
germ line cells in radiation-exposed individual animals, but also that the mutation rate increases considerably in non-irradiated offspring [88]. Studies in vitro indicate the long-lasting effect of an increased frequency of mutations in the offspring of irradiated parents: this effect persists for at least $20-40$ cell divisions taking place after the primary irradiation $[44,89,90]$.

Data concerning transgenerational genomic RIGI as a result of irradiation IR are, to a great extent, limited to males $[86,91,92,93]$, although studies on females have also been undertaken recently $[62,63,74,94,95]$. In early studies pertaining to this phenomenon, the genotoxic effects were evaluated at the prophase I stage (oocytes at the stage of pachyten, diploten and diktioten) in Chinese hamster [55, $56,57]$. After irradiation of the animals with a single dose of $1 \mathrm{~Gy}$, the researchers did not observe any considerable increase in chromosomal aberrations in one-cell embryos, nor developmental changes in the offspring of the irradiated females; also, no transgenerational effects were found with the use of measures applied in this study $[55,56,57]$. In a later study on mice, genotoxic effects were analyzed in the subsequent generations after irradiation of females at the zygote stage with a dose of $1 \mathrm{~Gy}$, which confirmed that in the subsequent generation of mice obtained after fertilization of these females by non-irradiated males, there occurred an approximately twice as high risk of prenatal mortality, but without a statistically significant increase in the frequency of occurrence of the malformed foetuses [60]. In turn, in a study by Jaquet et al. [32], an exposure of female mice at the zygote stage to low doses of radiation $(0.2$ and $0.4 \mathrm{~Gy}$ ) was not associated with the occurrence of genomic instability in the next generation of embryos; however, it was related with higher rates of pregnancy, less resorptions and more living foetuses, and additionally with a higher birth weight of foetuses [32].

The object of the study was also the relationship between transgenerational RIGI and gender of the irradiated animals. In a study by Abouzeid et al. [94], female mice were irradiated with a dose of $1 \mathrm{~Gy}$, and subsequently fertilized by nonirradiated males. In the first generation of offspring, the frequency of mutations was evaluated at expanded simple tandem repeat (ESTR) loci, both in the germline and somatic tissues. It was found that maternal irradiation had no effect on the stability of the genome in $\mathrm{F}_{1}$ offspring. Also, an earlier study by Barber et al. [95] showed that maternal in utero exposure to IR had no effect on the genetic stability in $\mathrm{F}_{1}$ offspring; however, genomic instability was observed while performing evaluation by the ESTR method in the case of $\mathrm{F}_{1}$ offspring of prenatally irradiated male mice. Justification of the results concerning females, which consist in the lack of occurrence of genomic instability in $\mathrm{F}_{1}$ offspring, requires further studies.

The phenomenon of chromosome instability in fibroblasts collected from foetuses irradiated at the zygote stage was confirmed as early as 1989 by Pampfer and Streffer [24]. The researchers found that the spontaneous structural aberrations observed in fibroblasts were mainly of the character of chromatid and chromosome fragments, and a significantly higher proportion of cells with micronuclei, were not directly induced by the exposure to IR, but were the result of genomic instability caused by irradiation of the zygote. The occurrence of transgenerational chromosomal instability in mice induced by irradiation during the preimplantation period, especially during the zygote stage, was confirmed by Streffer in 2006 [96]. However, the problem remains regarding the possibility of extrapolation of the result of studies concerning RIGI, to a great extent generated in the model in vitro to humans, the verification of the results obtained in vitro in studies in vivo, as well as the explanation of the mechanisms of this phenomenon [87]. Studies on humans are contradictory with respect to the occurrence of RIGI [87]. While discussing the results in this area, it is emphasized that the induction of RIGI in laboratory conditions takes place with the use of high doses of IR, which rarely concern humans, who are rather subjected to chronic exposure to low-dose radiation [87].

Studies concerning the occurrence of the transgenerational effects of irradiation in humans were conducted in the population exposed to atomic bombs (A-bombs) explosions in Hiroshima and Nagasaki. The results of follow-up studies including 120,000 survivors of these attacks, and 77,000 offspring which, according to the state in 2016, showed that the offspring of persons irradiated with the dose of an average of $200 \mathrm{mGy}$ (except for the immediate region of the epicentre of the explosions), were burdened neither with an elevated risk of occurrence of developmental abnormalities, nor a higher mutation rate, which means that no transgenerational effects of irradiation occurred [97; see also: 2]. The Radiation Effects Research Foundation (RERF) investigating the effects of the use of A-bombs in Hiroshima and Nagasaki states that among children of irradiated persons during the 6-year period of observation in the years 1948-1954 of 76,626 infants, no statistically significant increase was observed in the frequency of foetal damage, nor any other negative phenomena during pregnancy. The RERF indicates that the frequency of serious damage to newborns was $0.91 \%$, which did not differ from the values registered at this time among the Japanese population not exposed to A-bombs explosions [98].

Limitations and perspectives of studies of the effect of IR on female fertility. The data resources concerning health risk due to exposure of female germ cells to IR in humans are limited, and the majority of them are based on the results obtained from the analysis of exposure to IR originating from medical sources (radiotherapy), or related with nuclear accidents or explosions of A-bombs $[97,98,99]$. Data obtained in studies on animals indicate that radiosensitivity of the female germ cells varies according to species and follicle/ oocyte stage, with the highest susceptibility to the occurrence of mutational events being generally shown by the oocytes near ovulation [99]. Adriaens et al. suggested that the differences in the mutagenic sensitivity of the oocytes, to some extent are dependent on changes in the effectiveness of the mechanisms of DNA repair [99]. An important factor is also the size of oocytes: it is known that small oocytes are less susceptible to IR. Taking into account physiological similarities, it is suggested that the radiosensitivity of human follicles from the aspect of the stage of development, is similar to the radiosensitivity of follicles in guinea pigs, in which from the moment of 3 weeks before ovulation (late pre-antral stage) radiosensitivity begins to increase and reaches its peak 2 days before ovulation [99].

With respect to the data from studies in vivo, in the first place, let us consider the knowledge generated as a result of analyses of the effects of treatment with radiotherapy on female fertility. Sensitivity to the effects of radiotherapy 
(thus, also other types of irradiation) depends on the pool of available germ cells at a specified age. Exposure to environmental factors accelerates the reduction of the pool of available oocytes, which results in the acceleration of the occurrence of ovarian failure, loss of reproductive potential, and preterm occurrence of menopause [99]. As stated, the dose needed to destroy a half of the primordial follicles $\left(\mathrm{LD}_{50}\right)$ is estimated at below $2 \mathrm{~Gy}$ [48]. The effective sterilizing dose (ESD) according to age is: at birth - 20.3 Gy, at the age of $10-18.4 \mathrm{~Gy}$, at the age of $20-16.5 \mathrm{~Gy}$, and at the age of $30-14.3 \mathrm{~Gy}$ [99]. Metanalysis by Gao et al. [100] indicated a high frequency of infertility among women who had undergone radiotherapy during childhood $(\mathrm{R} R=1.28$, 95\% CI=1.16-1.42), the occurrence of acute ovarian failure $(\mathrm{RR}=9.51,95 \% \mathrm{CI}=5.03-17.96)$, low levels of anti-mullerian hormone $(\mathrm{AMH})(\mathrm{RR}=14.79,95 \% \mathrm{CI}=3.36-66.04)$, still birth $(\mathrm{RR}=1.19,95 \% \mathrm{CI}=1.02-1.39)$, and low birth weight $(\mathrm{RR}=2.22$, 95\% CI= 1.55-3.17), which evidences that radiotherapy during childhood exerts a negative effect on reproductive health in adulthood. The importance of the time elapsed, as well as individual differences for the effects of radiation observed, requires further studies [100].

Analyses of the effects of exposure to IR associated with explosions of A-bombs in the cities of Hiroshima and Nagasaki in a group of 2,345 women, indicated that 'no large long-range alterations in average fertility can be attributable to exposure to atomic radiation in $1945^{\prime}$ [101]. In turn, studies of the effects of the explosion in Chernobyl in 1986 demonstrated that neither in Byelorus nor in the Ukraine were significant changes observed in the prevalence at birth of anomalies, nor was there a prevalence of unfavourable outcomes of pregnancy which might be associated with the accident; however, indirect effects did occur, consisting in the performance of abortions in relation with fear of the occurrence of effects of irradiation [102]. Frequent occurrence of minisatelite mutations within the non-protein coding genes in children of persons exposed to IR in the contaminated areas after the accident in Chernobyl (Mogilev district of Belarus) were reported, and the intensity of this phenomenon was correlated with the level of caesium-137 surface contamination [103]. Nevertheless, these studies were subject to criticism [see: 99]. In turn, the results of a population-based descriptive epidemiology study by Wertelecki et al. [104], showed that in the Rivne province, located at a distance of $200 \mathrm{~km}$ from the site of explosion in Chernobyl, the rates of conjoined twins, teratomas, neural tube defects, microcephaly, and microphthalmia were among the highest in Europe. The Polissia region, a part of the Rivne province, is characterized by a significantly higher frequency of the occurrence of neural tube defects, microcephaly and microphthalmia; moreover, in this region, lower values of atbirth head size are observed, compared to the capital of the province [104]. Drawing conclusions concerning cause-effect relationships between the accident in Chernobyl and the epidemiology of congenital defects described in this research is hindered by the descriptive character of the quoted studies.

Within the range of low doses received by the majority of the population there is no unequivocal evidence for the occurrence of adverse pregnancy outcomes [99]. Within this range, a different effect of IR is suggested on adverse reproductive outcomes according to gender. In a study of an occupational cohort of the nuclear industry in the UK exposed to low-level IR, it was found that there was no relationship between the exposure to IR before conception and increased risk of adverse reproductive outcome in men working in the nuclear industry, whereas such a relationship was observed in women: the risk of early $(<13$ weeks of gestation) miscarriage was higher in mothers exposed to low doses of IR (OR 1.3, 95\% CI 1.0-1.6); the risk of stillbirth was also higher (OR 2.2, 95\% CI 1.0-4.6) [105].

A limitation of the existing data concerning the effects of IR on reproductive health, projecting on the possibility to formulate generalizations, is that the object of the study pertaining to the effects of exposure to IR were mostly males [99]. In turn, the extrapolation of results dominant in this area considering the effect of IR on animal germ cells, on humans is hindered by the fact that in animal lethal studies high acute exposures are applied, which do not reflect human environmental exposures, characteristic of chronic low dose exposure [21].

\section{CONCLUSIONS}

1. The effect of IR on female fertility concerns, according to the irradiated localization: in the case of irradiation of the abdominal cavity - function of the ovaries and uterus, and in the case of irradiation of the skull - H-P-G axis function.

2. Irradiation of the ovaries causes a reduction in the ovarian pool of follicles within the scope depending on the dose received, which may effect the premature ovarian failure, early menopause, or infertility.

3. Radiosensitivity of the oocytes depends on the IR dose, as well as on the stage of oogenesis/folliculogenesis.

4. Radiosensitivity of the female reproductive system is a species-specific characteristic.

5. Considering progress in the diagnostics and curability of childhood cancers, fertility counselling should be an integral element of paediatric oncology, as well as followup medical care of persons cured of childhood cancer.

\section{REFERENCES}

1. Cadet J, Davies KJA. Oxidative DNA damage \& repair: An introduction. Free Radic Biol Med. 2017; 107: 2-12. DOI: 10.1016/j. freeradbiomed.2017.03.030

2. Sankaranarayanan $\mathrm{K}$, Wassom JS. Ionizing radiation and genetic risks XIV. Potential research directions in the post-genome era based on knowledge of repair of radiation-induced DNA double-strand breaks in mammalian somatic cells and the origin of deletions associated with human genomic disorders. Mutat Res. 2005; 578(1-2): 333-370. DOI: 10.1016/j.mrfmmm.2005.06.020

3. Agarwal A, Parekh N, Panner Selvam MK, Henkel R, Shah R, Homa ST, et al. Male Oxidative Stress Infertility (MOSI): Proposed Terminology and Clinical Practice Guidelines for Management of Idiopathic Male Infertility. World J Mens Health. 2019; 37(3): 396-312. DOI: 10.5534/ wjmh.190055

4. Wdowiak A, Bakalczuk G, Bakalczuk S. Evaluation of effect of selected trace elements on dynamics of sperm DNA fragmentation. Post Hig Med Dosw. 2015; 69: 1405-1410.

5. Wdowiak A, Wiktor H, Wdowiak L. Maternal passive smoking during pregnancy and neonatal health. Ann Agric Environ Med. 2009; 16(2): 309-312.

6. Wdowiak A, Lewicka M, Plewka K, Bakalczuk G. Nicotinism and quality of embryos obtained in in-vitro fertilization programmes. Ann Agric Environ Med. 2013; 20(1): 82-85. DOI: 10.26444/ aaem/75422

7. Michalak A, Krzeszowiak J, Markiewicz-Górka I. The correlations between aging of the human body, oxidative stress and reduced efficiency of repair systems. Post Hig Med Dosw. 2014; 68: 1483-1491. 
8. Wdowiak A, Mazurek PA, Wdowiak A, Bojar I. Effect of electromagnetic waves on human reproduction. Ann Agric Environ Med. 2017: 24(1): 13-18. DOI: 10.5604/12321966.1228394

9. Wdowiak A, Skrzypek M, Stec M, Panasiuk L. Effect of ionizing radiation on the male reproductive system. Ann Agric Environ Med. 2019; 26(2): 210-216. DOI: $10.26444 /$ aaem/106085

10. Skrzypek M, Wdowiak A, Marzec A. Application of dietetics in reproductive medicine. Ann Agric Environ Med. 2017; 24(4): 559-565. DOI: $10.26444 /$ aaem/76997

11. Stańczak J, Cierniak-Piotrowska M, Stelmach K, Znajewska A. [Demographic situation in Poland up to 2017. Births and fertility]. Warszawa: Zakład Wydawnictw Statystycznych; 2018. p. 12-13. [In Polish].

12. Stańczak J, Znajewska A. [Population. Size and structure and vital statistics in Poland by territorial division in 2018. As of December, 31]. Warszawa: Zakład Wydawnictw Statystycznych; 2019. p. 12. [In Polish]

13. Sawicka M. [Maternity is mostly associated with young women] Rodzina w czasach szybkich przemian, Roczniki Socjologii Rodziny. Poznań: Adam Mickiewicz University Press; 2001. p. 245-257. [In Polish].

14. Szukalski P. [Demography and social gerontology - information bulletin]. 2012; 6: 1-4. Available fom: http://dspace.uni.lodz.pl:8080/ xmlui/bitstream/handle/11089/5325/2014-08\%20Sex\%20ratio. pdf? sequence=1 (access: 2019.07.07). [In Polish].

15. Dutreix J, Wambersie A. Introduction to radiobiology. Tailor\&Praxis, London, New York, 1990

16. Marci R, Mallozzi M, Di Benedetto L, Schimberni M, Mossa S, Soave I, et al. Radiations and female fertility. Reprod Biol Endocrinol. 2018; 16(1): 112. DOI: 10.1186/s12958-018-0432-0

17. Shahbazi MN, Siggia ED, Zernicka-Goetz M. Self-organization of stem cells into embryos: A window on early mammalian development. Science. 2019; 364(6444): 948-951. DOI: 10.1126/science.aax0164

18. Richardson BE, Lehmann R. Mechanisms guiding primordial germ cell migration: strategies from different organisms. Nat Rev Mol Cell Biol. 2010; 11(1): 37-49. DOI: 10.1038/nrm2815

19. Grygoruk C, Sieczyński P, Ratomski K, Grusza M, Mrugacz G. [Select aspects of oogenesis and folliculogenesis]. Studia Medyczne. 2013. 29(2): 199-202. [In Polish].

20. Baker T.G. Comparative aspects of the effects of radiation during oogenesis. Mutat Res. 1971; 11: 9-22. DOI: 10.1016/0027-5107(71)900285

21. Adler ID, Carere A, Eichenlaub-Ritter U, Pacchierotti F. Gender differences in the induction od chromosomal aberrations and gene mutations in rodent germ cells. Environ Res. 2007; 104: 37-45. DOI: $10.1016 /$ j.envres.2006.10.002

22. Krajewski P. [Biological effects of ionizing radiation]. Warsaw: Central Laboratory for Radiological Protection, Faculty of Physics, Warsaw University of Technology; 2009. Available from: www.if.pw.edu.pl (access: 2019.01.24). [In Polish].

23. Valerie K, Povirk LF. Regulation and mechanisms of mammalian double-strand break repair. Oncogene. 2003; 22(37): 5792-5812. DOI: $10.1038 /$ sj.onc. 1206679

24. Pampfer S, Streffer C. Increased chromosome aberration levels in cells from mouse fetuses after zygote $\mathrm{x}$-irradiation. Int J Radiat Biol. 1989; 55(1): 85-92.

25. Goedecke W, Eijpe M, Offenberg HH, van Aalderen M, Heyting C. Mre11 and Ku70 interact in somatic cells, but are differentially expressed in early meiosis. Nat Genet. 1999; 23(2): 194-198. DOI: $10.1038 / 13821$

26. Hamer G, Roepers-Gajadien HL, van Duyn-Goedhart A, Gademan IS $\mathrm{Kal} \mathrm{HB}$, van Buul PP, et al. Function of DNA-protein kinase catalytic subunit during the early meiotic prophase without Ku70 and Ku86. Biol Reprod. 2003; 68(3): 717-721. DOI: 10.1095/biolreprod.102.008920

27. Cox BD, Lyon MF. X-ray induced dominant lethal mutations in mature and immature oocytes of guinea-pigs and golden hamsters. Mutat Res. 1975; 28: 421-436. DOI: 10.1016/0027-5107(75)90236-5

28. Tease C. Dose-related chromosome non-disjunction in female mice after X-irradiation of dictyate oocytes. Mutat Res. 1985; 151: 109-119. DOI: 10.1016/0027-5107(85)90189-7

29. Caine A, Lyon MF. The induction of chromosome aberrations in mouse dictyate oocytes by X-rays and chemical mutagens. Mutat Res. 1977; 45, 325-331. DOI: 10.1016/0165-1110(92)90037-A

30. Kirk M, Lyon MF. Induction of congenital anomalies in offspring of female mice exposed to varying doses of X-rays. Mutat Res. 1982; 106: 73-83. DOI: $10.1016 / 0027-5107(82) 90191-9$

31. Griffin CS, Tease C, Fisher G. The effect of low-dose x-irradiation on numerical and structural chromosome anomaly induction in mouse immature oocytes. Mutat Res. 1990; 231: 137-142. DOI: 10.1016/00275107(90)90020-5

32. Jacquet P, Buset J, Neefs M, Vankerkom J, Benotmane MA, Derradji $\mathrm{H}$, et al. Transgenerational developmental effects and genomic instability after $\mathrm{x}$-irradiation of preimplantation embryos: Studies on two mouse strains. Mutat Res. 2010; 687: 54-62. DOI: 10.1016/j. mrfmmm.2010.01.013

33. Jacquet P, Buset J, Vankerkom J, Baatout S, de Saint-Georges L, Baugnet-Mahieu L, et al. Radiation-induced chromosome aberrations in guinea-pig growing oocytes, and their relation to follicular atresia. Mutat Res. 2001; 473: 249-254. DOI: 10.1016/S0027-5107(00)00153-6

34. Johannisson R, Mormel R, Brandenburg B. Synaptonemal complex damage in fetal mouse oocytes induced by ionizing irradiation. Mutat Res. 1994; 311: 319-328. DOI: 10.1016/0027-5107(94)90190-2

35. Mikamo K. Meiotic chromosomal radiosensitivity in primary oocytes of the Chinese hamster. Cytogenet Cell Genet. 1982; 33: 88-94. DOI: $10.1159 / 000131731$

36. Pan H, O' Brien MJ, Wigglesworth K, Eppig JJ, Schultz RM. Transcription profiling during mouse oocyte development and the effect of gonadotropin priming and development in vitro. Dev Biol. 2005; 286: 493-506. DOI: 10.1016/j.ydbio.2005.08.023

37. Tease $\mathrm{C}$, Fisher $\mathrm{G}$. The influence of maternal age on radiation-induced chromosome aberrations in mouse oocytes. Mutat Res. 1991; 262: 57-62. DOI: 10.1016/0165-7992(91)90107-f

38. Tease C, Fisher G. X-ray-induced chromosome aberrations in immediately preovulatory oocytes. Mutat Res. 1986; 173: 211-215. DOI: $10.1016 / 0165-7992(86) 90038-2$

39. Mavragani VI, Laskaratou DA, Frey B, Candéias SE, Gaip US, Lumniczky K, et al. Key mechanisms involved in ionizing radiation induced systemic effects. A current review. Toxicol Res. 2016; 5: 12. DOI: $10.1039 / \mathrm{c} 5 \mathrm{tx} 00222 \mathrm{~b}$

40. Smith LE, Nagar S, Kim GJ, Morgan WF. Radiation-induced genomic instability: Radiation quality and dose response. Health Phys. 2003; 85: $23-29$.

41. Camats N, Garcia F, Parrilla JJ, Calaf, Martin-Mateo M, Caldes MG. The GnRH analogue triptorelin confers ovarian radio-protection to adult female rats. Mutat Res. 2009; 669: 67-79. DOI: 10.1016/j. mrfmmm.2009.05.002

42. Morgan WF. Is there a common mechanism underlying genomic instability, bystander effects and other nontargeted effects of exposure to ionizing radiation? Oncogene. 2003; 22: 7094-7099. DOI: 10.1038/ sj.onc. 1206992

43. Nagasava H, Little JB. Induction of sister chromatid exchanges by extremely low doses of a-particles. Cancer Res. 1992; 52: 6394-6396.

44. Lorimore SA, Coates PJ, Wrihgt EG. Radiation-induced genomic instability and bystander effects: inter-related nontargeted effects of exposure to ionizing radiation. Oncogene. 2003; 22: 7058-7069. DOI: $10.1038 /$ sj.onc. 1207044

45. Moens PB, Kolas NK, Tarsounas M, Marcon E, Cohen PE, Spyropoulos $B$. The time course and chromosomal localization of recombinationrelated proteins at meiosis in the mouse are compatible with models that can resolve the early DNA-DNA interactions without reciprocal recombination. J Cell Sci. 2002; 115: 1611-1622.

46. Baker SM, Plug AW, Prolla TA, Bronner CE, Harris AC, Yao X, et al Involvement of mouse Mlh1 in DNA mismatch repair and meiotic crossing over. Nat Genet. 1996; 13: 336-342. DOI: 10.1038/ng0796-336

47. Turner JM, Aprelikova O, Xu X, Wang R, Kim S, Chandramouli GV, et al. BRCA1, histone H2AX phosphorylation, and male meiotic sex chromosome inactivation. Curr Biol. 2004; 14: 2135-2142. DOI: 10.1016/j.cub.2004.11.032

48. Wallace WH, Thomson AB, Kelsey TW. The radiosensitivity of the human oocyte. Hum Reprod. 2003: 18(1): 117-121. DOI: 10.1093/ humrep/deg016

49. Wallace WH, Thomson AB, Saran F, Kelsey TW. Predicting age of ovarian failure after radiation to a field that includes the ovaries. Int Radiat Oncol Biol Phys. 2005; 62: 738-744. DOI:10.1016/j. ijrobp.2004.11.038

50. Diehn M, Cho RW, Clarke MF. Therapeutic implications of the cancer stem cell hypothesis. Semin Radiat Oncol. 2009; 19: 78-86. DOI: 10.1016/j.semradonc.2008.11.002

51. Jacquet P, de Saint-Georges L, Vankerkom J, Baugnet-Mahieu L. Embryonic death, dwarfism and fetal malformations after irradiation of embryos at the zygote stage: Studies on two mouse strains. Mutat Res. 1995; 332: 73-87. DOI: 10.1016/0027-5107(95)00156-4

52. Beaumont HM. The effects of acute $\mathrm{x}$-irradiation on primordial germcells in the female rat. Int J Radiat Biol Relat Stud Phys Chem Med. 1966; 10: 17-28. 
53. Pujol R, Cusido L, Rubio A, Egozcue J, Garcia M. Effect of X-rays on germ cells in female fetuses of Rattus norvegicus irradiated at three different times of gestation. Mutat Res. 1996: 356: 247-253. DOI: 10.1016/0027-5107(96)00067-X

54. Pujol R, Cusido L, Rubio A, Egozcue J, Garcia M. X-ray-induced synaptonemal complex damage during meiotic prophase in female fetuses of Rattus norvegicus. Mutat Res. 1997; 379: 127-134. DOI: 10.1016/s0027-5107(97)00115-2

55. Tateno H, Mikamo K. Effects of neonatal ovarian x-irradiation in the Chinese hamster. Correlation between the age of irradiation and the fertility span. J Radiat Res. 1989; 30: 185-190. DOI: 10.1269/jrr.30.209

56. Tateno H, Mikamo K. Effects of neonatal ovarian x-irradiation in the Chinese hamster. II. Absence of chromosomal and developmental damages in surviving oocytes irradiated at the pachytene and resting dictyate stages. J Radiat Res. 1989; 30: 209-217. DOI: 10.1269/jrr.30.209

57. Tateno H, Mikamo K. Neonatal oocyte development and selective oocyte-killing by X-rays in the Chinese hamster, Cricetulus griseus. Int J Radiat Biol Relat Stud Phys Chem Med. 1984; 45: 139-149.

58. Jacquet P, de Saint-Georges L, Buset J, Baatout S, Vankerkom J, Baugnet-Mahieu L. Cytogenetic effects of x-rays in the guinea pig female germ cells. II. The maturing oocyte. Mutat Res. 1997; 391: 193-199. DOI: 10.1016/s1383-5718(97)00068-5

59. Jacquet P, Vankerkom J, Lambiet-Collier $M$. The female guinea pig, a useful model for the genetic hazard of radiation in man; preliminary results on germ cell radiosensitivity in foetal, neonatal and adult animals. Int J Radiat Biol. 1994; 65: 357-367. DOI: 10.1080/09553009414550421

60. Pils S, Muller WU, Streffer C. Lethal and teratogenic effects in two successive generations of the hlg mouse strain after radiation exposure of zygotes- Association with genomic instability? Mutat Res. 1999; 429: 85-92. DOI: 10.1016/s0027-5107(99)00101-3

61. Camats N, Garcia F, Parrilla JJ, Calaf J, Martin-Mateo M, Caldes MG. The GnRH analogue triptorelin confers ovarian radio-protection to adult female rats. Mutat Res. 2009; 669: 67-79. DOI: 10.1016/j. mrfmmm.2009.05.002

62. Martinez-Flores I, Egozcue J, Garcia M. Effects on female fertility and germinal cells in prepubertal and adult rats (Rattus norvegicus) after X-ray irradiation. Adv Exp Med Biol. 1998; 444: 215-219. DOI: 10.1007/978-1-4899-0089-0_25

63. Martinez-Flores I, Saez C, Egozcue J, Garcia M. Effects of ionizing radiation on oocytes of prepubertally irradiated rats. Int J Radiat Biol. 2000: 76: 1403-1407. DOI: 10.1080/09553000050151682

64. Brewen JG, Payne HS, Preston RJ. X-ray-induced chromosome aberrations in mouse dictyate oocytes. I. Time and dose relationships. Mutat Res. 1976; 35: 111-120. DOI: 10.1016/0027-5107(76)90173-1

65. Brewen JG, Payne HS. X-ray-induced chromosome aberrations in mouse dictyate oocytes. II. Fractionation and dose rate effects. Genetics. 1977; 87: 699-708.

66. Hansmann I, Jenderny J, Probeck HD. Nondisjunction and chromosome breakage in mouse oocytes after various X-ray doses. Hum Genet. 1982: 61: 190-192. DOI: 10.1007/bf00296439

67. Reichert W, Buselmaier W, Vogel F. Elimination of X-ray-induced chromosomal aberrations in the progeny of female mice. Mutat Res. 1984; 139: 87-94. DOI: 10.1016/0165-7992(84)90109-x

68. Reichert W, Hansmann I, Rohrborn G. Chromosome anomalies in mouse oocytes after irradiation. Humangenetik. 1975; 28: 25-38.

69. Yang F, Wang PJ. The mammalian synaptonemal complex: a scaffold and beyond. Genome Dyn. 2009; 5: 69-80. DOI: 10.1159/000166620

70. Dobson MJ, Pearlman RE, Karaiskakis A, Spyropoulos B, Moens PB. Synaptonemal complex proteins: Occurrence, epitope mapping and chromosome disjunction. J Cell Sci. 1994; 107: 2749-2760.

71. Kouznetsova A, Benavente R, Pastink A, Hoog C. Meiosis in mice without a synaptonemal complex. PLoS One. 2011; 6(12): e2855. DOI: 10.1371/journal.pone.0028255.

72. Cusido L, Pujol R, Egozcue J, Garcia M. Cyclophosphamide-induced synaptonemal complex damage during meiotic prophase of female Rattus norvegicus. Mutat Res. 1995; 329: 131-141. DOI: 10.1016/00275107(95)00029-i

73. Allen JW, de Weese GK, Gibson JB, Poorman PA, Moses MJ. Synaptonemal complex damage as a measure of chemical mutagen effects on mammalian germ cells. Mutat Res. 1987; 190: 19-24. DOI: 10.1016/0165-7992(87)90076-5

74. Jacquet P, Adriaens I, Buset J, Neefs M, Vankerkom J. Cytogenetic studies in mouse oocytes irradiated in vitro at different stages of maturation, by use of an early preantral follicle culture system. Mutat Res. 2005; 583: 168-177. DOI: 10.1016/j.mrgentox.2005.03.008

75. Russell LB, Russell WL. The Sensitivity of Different Stages in Oogenesis to the Radiation Induction of Dominant Lethals and other Changes in the Mouse. In: Mitchell JS, Holmes BE, Smith CC, editors. Progress in Radiobiology. Edinburgh, UK: Oliver and Boyd Ltd.; 1956. p. 187192.

76. Russell WL. Effect of the interval between irradiation and conception on mutation frequency in female mice. Proc Natl Acad Sci USA. 1965; 54: 1552-1557. DOI: 10.1073/pnas.54.6.1552

77. Kamiguchi Y, Mikamo K. Dose-response relationship for induction of structural chromosome aberrations in Chinese hamster oocytes after x-irradiation. Mutat Res. 1982; 103: 33-37. DOI: 10.1016/01657992(82)90083-5

78. Edwards RG, Searle AG. Genetic radiosensitivity of specific postdictyate stages in mouse oocytes. Genet Res. 1963; 4: 389-398. DOI: $10.1017 /$ S0016672300003785

79. Mandl AM. The radiosensitivity of oocytes at different stages of maturation. Proc R Soc Lond Ser. 1963; 158: 119-141. DOI: 10.1098/ rspb.1963.0038

80. Ashwood-Smith MJ, Edwards RG. DNA repair by oocytes. Mol Hum Reprod. 1996; 2: 46-51. DOI: 10.1093/molehr/2.1.46

81. Hamatani T, Yamada M, Akutsu H, Kuji N, Mochimaru Y, Takano, $\mathrm{M}$, et al. What can we learn from gene expression profiling of mouse oocytes? Reproduction. 2008; 135: 581-592. DOI: 10.1530/REP-070430

82. Menezo Y, Russo G, Tosti E, El Mouatassim S, Benkhalifa M. Expression profile of genes coding for DNA repair in human oocytes using pangenomic microarrays, with a special focus on ROS linked decays. J Assist Reprod Genet. 2007; 24: 513-520. DOI: 10.1007/s10815007-9167-0

83. Su YQ, Sugiura K, Woo Y, Wigglesworth K, Kamdar S, Affourtit J, et al. Selective degradation of transcripts during meiotic maturation of mouse oocytes. Dev Biol. 2007; 302: 104-117. DOI: 10.1016/j. ydbio.2006.09.008

84. Zheng P, Schramm RD, Latham KE. Developmental regulation and in vitro culture effects on expression of DNA repair and cell cycle checkpoint control genes in rhesus monkey oocytes and embryos. Biol Reprod. 2005; 72: 1359-1369. DOI: 10.1095/biolreprod.104.039073

85. Wang S, Kou Z, Jing Z, Zhang Y, Guo X, Dong M, et al. Proteome of mouse oocytes at different developmental stages. Proc Nat Acad Sci USA. 2010; 107: 17639-17644. DOI: 10.1073/pnas.1013185107

86. Barber RC, Dubrova YE. The offspring of irradiated parents, are they stable? Mutat Res. 2006; 598: 50-60. DOI: 10.1016/j. mrfmmm.2006.01.009

87. Dubrowa YE. Genomic instability in the offspring of irradiated parents: facts and interpretations. Genetika. 2006; 42(10): 1116-1126.

88. Lüning KG, Frölen H, Nilsson A. Genetic effects of $239 \mathrm{Pu}$ salt injections in male mice. Mutat Res. 1976; 34: 539-542.

89. Morgan WF. Non-targeted and delayed effects of exposure to ionizing radiation: I. Radiation-induced genomic instability and bystander effects in vitro. Radiat Res. 2003; 159(5): 567-580. DOI: 10.1667/0033-7587(2003)159[0567:nadeoe]2.0.co;2

90. Morgan WF. Non-targeted and delayed effects of exposure to ionizing radiation: II. Radiation-induced genomic instability and bystander effects in vivo, clastrogenic factors and transgeneratnal effects. Radiat Res. 2003;159(5): 581-596. DOI: 10.1667/0033-7587(2003)159[0581:na deoe $] 2.0 . \operatorname{co} ; 2$

91. Dubrova YE, Plumb M, Brown J, Boulton E, Goodhead D, Jeffreys AJ. Induction of minisatellite mutations in the mouse germline by low-dose chronic exposure to gamma-radiation and fission neutrons. Mutat Res. 2000; 453: 17-24. DOI: 10.1016/s0027-5107(00)00068-3

92. Shiraishi K, Shimura T, Taga M, Uematsu N, Gondo Y, Ohtaki $\mathrm{M}$, et al. Persistent induction of somatic reversions of the pinkeyed unstable mutation in F1 mice born to fathers irradiated at the spermatozoa stage. Radiat Res. 2002; 157: 661-667. DOI: 10.1667/0033-7587(2002)157[0661:PIOSRO]2.0.CO;2

93. Vorobtsova IE. Irradiation of male rats increases the chromosomal sensitivity of progeny to genotoxic agents. Mutagenesis. 2000; 15: 33-38. DOI: 10.1093/mutage/15.1.33

94. Abouzeid Ali HE, Barber RC, Dubrova YE. The effects of maternal irradiation during adulthood on mutation induction and transgenerational instability in mice. Mutat Res. 2012; 732: 21-25. DOI: $10.1016 /$ j.mrfmmm.2012.01.003

95. Barber RC, Hardwick RJ, Shanks ME, Glen CD, Mughal SK, Voutounou $\mathrm{M}$, et al. The effects of in utero irradiation on mutation induction and transgenerational instability in mice. Mutat Res. 2009; 664: 6-12. DOI: 10.1016/j.mrfmmm.2009.01.011

96. Streffer C. Transgenerational transmission of radiation damage: Genomic instability and congenital malformation. J Radiat Res. 2006; 47: 19-24. 
97. Jordan BR. The Hiroshima/Nagasaki survivor studies: discrepancies between results and general perception. Genetics. 2016; 203: 1505 1512. DOI: $10.1534 /$ genetics.116.191759

98. Radiation Effects Research Foundation. Birth defects among the children of atomic-bomb survivors (1948-1954) Available from: https:// www.rerf.or.jp/en/programs/roadmap_e/health_effects-en/geneefxen/birthdef/ (access 2019.07.08)

99. Adriaens I, Smitz J, Jacquet P. The current knowledge on radiosensitivity of ovarian follicle development stages. Hum Reprod Update. 2009; 15 359-377. DOI: 10.1093/humupd/dmn063

100. Gao W, Liang JX, Yan Q. Exposure to radiation therapy is associated with female reproductive health among childhood cancer survivors: a meta-analysis study. J Assist Reprod Genet. 2015; 32(8): 1179-1186. DOI: $10.1007 /$ s10815-015-0490-6

101. Blot WJ, Sawada H. Fertility among female survivors of the atomic bombs of Hiroshima and Nagasaki. Am J Hum Genet. 1972; 24 613-622.
102.Little J. The Chernobyl accident, congenital anomalies and other reproductive outcomes. Paed Per Epid. 1993; 7: 121-151. DOI: 10.1111/ j.1365-3016.1993.tb00388.x

103. Dubrova YE, Nesterov VN, Krouchinsky NG, Ostapenko VA, Neumann R, Neil DL, et al. Human minisatellite mutation rate after the Chernobyl accident. Nature. 1996; 380: 683-686. DOI: 10.1038/380683a0

104. Wertelecki W, Yevtushok L, Zymak-Zakutnia N, Wang B, Sosyniuk Z, Lapchenko S, et al. Blastopathies and microcephaly in a Chernobyl impacted region of Ukraine. Con Anomalies. 2014; 54: 125-149. DOI: 10.1111/cga.12051

105. Doyle P, Maconochie N, Roman E, Davies G, Smith PG, Beral V. Fetal death and congenital malformation in babies born to nuclear industry employees: report from the nuclear industry family study. Lancet. 2000; 356(9238): 1293-1299. DOI: 10.1016/S0140-6736(00)02812-9

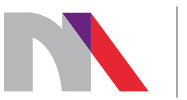

Ministry of Science and Higher Education

Republic of Poland

Generation of the DOI (Digital Object Identifier) - task financed under the agreement No. 618/P-DUN/2019 by the Minister of Science and Higher Education 